Gut, 1971, 12, 933-935

\title{
Lymphatic cysts of the colon
}

\author{
T. G. GIRDWOOD AND L. D. PHILP \\ From the Department of Radiodiagnosis, Cumberland Infirmary, Carlisle
}

SUMmARY A patient with a lymphatic cyst of the descending colon is reported. He underwent segmental resection of the colon. The clinical features, pathology, radiology, and treatment of these lesions are reviewed. It is emphasized that these cysts are very rare and cannot be diagnosed radiologically, but must be included in the differential diagnosis of polypoid lesions of the colon.

Lymphatic cysts (cystic lymphangiomata, lymphangiomatous, lymphangiectatic, or chylous cysts) of the abdomen are rare and can occur in the mesentery, omentum, retroperitoneum, and very occasionally in the wall of the stomach, duodenum, and the small or large intestine.

The extreme rarity of the lesion and the interesting radiological appearances and differential diagnosis warrant the report of a case and a brief review of the literature.

\section{Case Report}

A 65-year-old man reported a three-month history of left-sided abdominal colic and melaena. He had a normal bowel habit and there was no vomiting.

On examination there was guarding and tenderness in the central abdomen and left hypochondrium. No mass could be palpated.

Rectal and sigmoidoscopic examinations were negative. Double-contrast barium enema study demonstrated a large, smoothly outlined and well circumscribed polypoidal lesion with a broad base on the medial wall of the descending colon (Figs. 1 and 2). There was diverticular disease of the sigmoid colon.

At laparotomy the polypoidal mass was palpated in the upper third of the descending colon, but suddenly disappeared. (Subsequently, this was found to be due to rupture and emptying of the cyst during palpation.) A segmental resection was undertaken. The resected colon was opened and a large redundant fold of mucosa was found which was clearly all that remained of a ruptured cyst. The lesion was inflated with water and a photograph taken (Fig. 3).

Received for publication 26 June 1971.

\section{Pathology}

The inflated specimen was thin walled and measured $2.5 \mathrm{~cm}$ in diameter.

Histology revealed a large unilocular submucosal cyst lined with flattened endothelium and the appearances were in keeping with those of a lymphatic cyst. There was no evidence of malignant change.

\section{Discussion}

Lymphatic cysts of the gut are extremely rare entities. A review of these cysts at the Mayo Clinic over a 36-year period revealed nine cases; six of these were found in the mesentery, two in the retroperitoneum, and one was of undetermined origin. No mural cysts of the alimentary tract were reported (Beahrs, Judd, and Dockerty, 1950).

A more recent 10 -year review at the same clinic found nine cases; two of these had multiple cysts scattered throughout serosa, omentum, peritoneum, and broad ligament. The remaining seven patients had single submucosal cysts of which three were in duodenum, two in stomach, one in jejunum, and one in colon (Fleming and Carlson, 1970).

To date there have been six cases of lymphatic cysts of the colon documented; one was found in the ascending colon (Arnett and Friedman, 1956), one in the hepatic flexure (Alvich and Lepow, 1960), three in the transverse colon (Koenig, Claudon, and Byrne, 1955; Higgason, 1958; Greene, Kirshen, and Greene, 1962), and one in the descending colon (Fleming and Carlson, 1970).

The majority of cases reported in the literature have presented with abdominal pain. Greene et al (1962) documented a case in which the patient presented with bleeding from the rectum as in our 


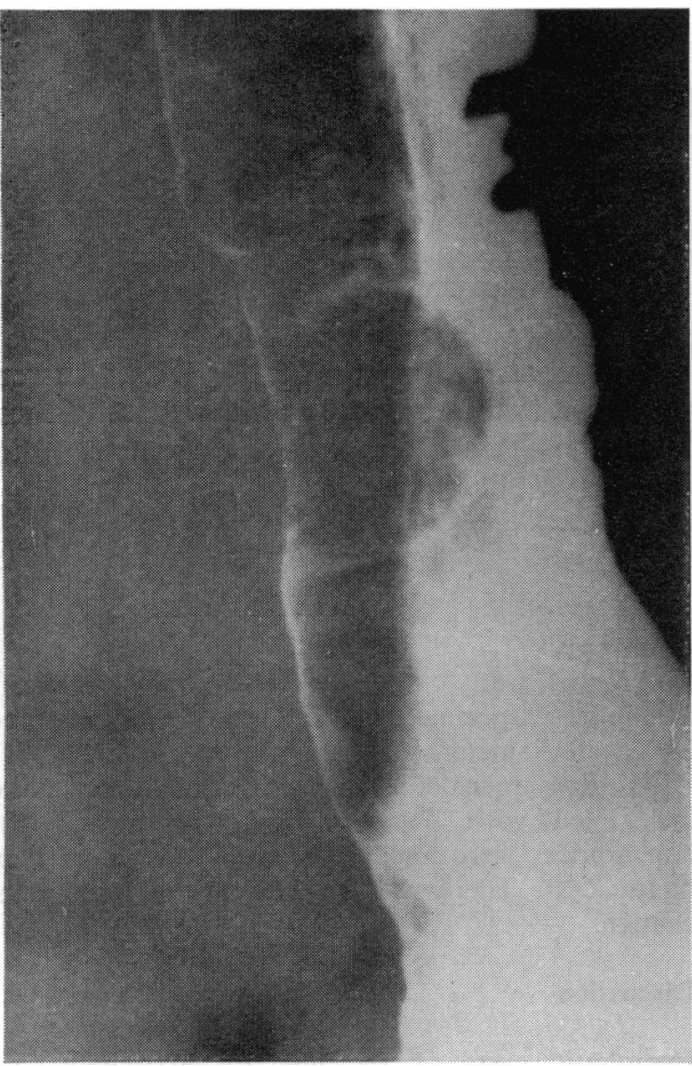

Fig. 1 Double-contrast barium enema, anteroposterior view of descending colon, with the patient lying on his left side.

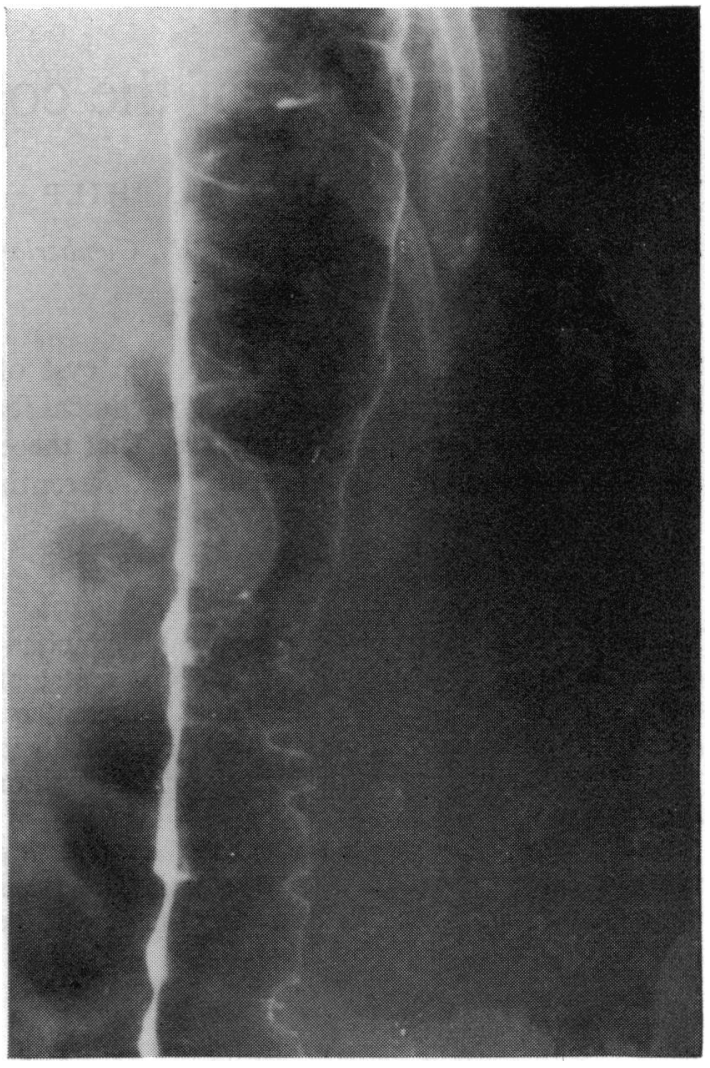

Fig. 2 Anteroposterior view, with the patient lying on his right side.

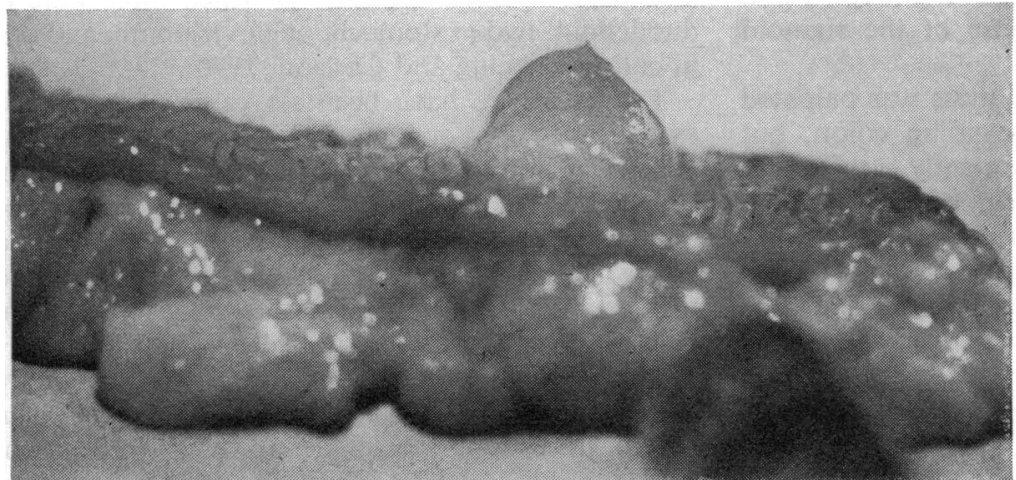

Fig. 3 The specimen inflated with water. 
case. However, our patient had diverticular disease which could also have accounted for this latter finding and the abdominal pain.

Intestinal lymphatic cysts are thin walled, uni- or multilocular, are submucosal and contain serous fluid. Their aetiology is uncertain. Gerster (1939) has shown that cystic lymphangiomata may arise from cavernous lymphangiomata and may have cavernous lymphatic tissue in their walls.

Arnett and Friedman (1956) first described the radiological appearences of the lesion as 'a sharply marginated peripheral oval to round colonic defect indicating an intramural location. It is associated with an intact mucosa.' They also stated that it had a variable contour and that distension of the colon with air caused the lesion to disappear. We did not find this on double-contrast enema study, but we did observe that the lesion changed in shapefrom an ovoid to a sphere from one radiograph to another (Figs. 1 and 2).

In view of the very similar appearances to colonic polyps and the fact that two of these cysts were pedunculated (Koenig et al, 1955; Greene et al, 1962), it is not surprising to find that they have never been diagnosed radiologically. The differential diagnosis must include adenomatous polyp, submucosal lipoma, leiomyoma, enterogenous cyst, and cavernous haemangioma-in that order. Of the cysts connected with or adjacent to the colon, the enterogenous cyst is probably the most common but is normally found in the ileocaecal or rectosigmoid area.
Resection of bowel is said to be preferable to simple excision of the lesion since Beahrs et al (1950) reported that two of their nine cases of extraintestinal cysts were found to be malignant and Higgason (1958) drew attention to the fact that a large diverticulum may form at the site of the cyst bed after local resection due to weakening of the intestinal wall.

We wish to thank Mr R. D. Peduzzi for permission to publish this case report, Dr J. A. S. Amos for the pathological report, and Dr W. G. Scott-Harden for his helpful criticism in the preparation of this paper. Our thanks are also due to Miss H. Lindsay and her staff for the excellent radiographs and the Department of Medical Photography, University of Newcastle-upon-Tyne for the photographic prints.

\section{References}

Alvich, J. P., and Lepow, H. 1. (1960). Cystic lymphangioma of hepatic flexure of colon. Ann. Surg., 152, 880-884.

Arnett, N. L., and Friedman, P. S. (1956) Lymphangioma of the colon: roentgen aspects: a case report. Radiology, 67, 882-885.

Beahrs, O. H., Judd, E. S., Jr., and Dozkerty, M. B. (1950). Chylous cysts of the abdomen. Surg. Clin. N. Amer., 30, 1081-1096.

Fleming, M. P., and Carlson, H. C. (1970). Submucosal lymphatic cysts of the gastrointestinal tract; a rare cause of submucosal mass lesion. Amer. J. Roentgenol., 110, 842-845.

Gerster, J. C. A. (1939). Retroperitoneal chyle cysts; with especial reference to the lymphangiomata. Ann. Surg., 110, 389-410.

Greene, E. I., Kirshen, M. M., and Greene, J. M. (1962). Lymphangioma of the transverse colon. Amer. J. Surg., 103, 723-726.

Higgason, J. M. (1958). Lymphatic cyst of the transverse colon. Amer. J. Roentgenol., 79, 850-853.

Koenig, R. R., Claudon, D. B., and Byrne, R. W. (1955). Lymphatic cyst of transverse colon. Arch. Path., 60, 431-434. 